\title{
Hydration Process as an Activation of Trans- and Cisplatin Complexes in Anticancer Treatment. DFT and $A b$ Initio Computational Study of Thermodynamic and Kinetic Parameters
}

\author{
JAROSLAV V. BURDA, ${ }^{1}$ MICHAL ZEIZINGER, ${ }^{1}$ JERZY LESZCZYNSKI ${ }^{2}$ \\ ${ }^{1}$ Department of Chemical Physics and Optics, Faculty of Mathematics and Physics, \\ Charles University, Ke Karlovu 3, Prague 2, 121 16, Czech Republic \\ ${ }^{2}$ Department of Chemistry, Jackson State University, 1325 J. R. Lynch Street, \\ Jackson, Mississippi 39217-0510 \\ Received 3 January 2005; Accepted 22 February 2005 \\ DOI 10.1002/jcc. 20228 \\ Published online in Wiley InterScience (www.interscience.wiley.com).
}

\begin{abstract}
The thermodynamic and kinetic aspects of hydration reactions of cis-/transplatin were explored. The polarizable continuum model was used for estimation of solvent effects. Using the B3LYP/6-31+G(d) method, the structures were optimized and vibrational frequencies estimated. Interaction energies and activation barriers were determined at the CCSD(T)/6-31++G(d,p) level within the COSMO approach. An associative mechanism was assumed with a trigonal-bipyramidal structure of the transition state. Within the applied model, all the hydration reactions are slightly endothermic. The Gibbs energies of cisplatin hydration amount to 7.0 and $14.2 \mathrm{kcal} / \mathrm{mol}$ for the chloride and ammonium replacement, respectively. Analogous values for the transplatin reactions are 6.8 and $11.9 \mathrm{kcal} / \mathrm{mol}$. The determined rate constants are by several (three to four) orders of magnitude larger for the dechlorination process than for deammination. The cisplatin dechlorination rate constant was established as $1.3 \cdot 10^{-4} \mathrm{~s}^{-1}$ in excellent accord with the experiment.
\end{abstract}

(C) 2005 Wiley Periodicals, Inc. J Comput Chem 26: 907-914, 2005

Key words: hydration process; transplatin; cisplatin; anticancer treatment

\section{Introduction}

Cisplatin (cis-dichlorodiammineplatinum, cisDDP) has been one of the most frequently explored platinum compound since Rosenberg's discovery of its anticancer activities. ${ }^{1}$ Later, it was recognized that the cisplatin forms the bridge connection between two (usually) adjacent guanines in DNA, forming an intrastand 1,2$\mathrm{d}(\mathrm{GpG})$ complex. The high mobility group (HMG) protein can recognize the bend on such a platinated DNA $\alpha$-helix and bind to it. $^{2}$ These ternary Pt-DNA-HMG complexes were characterized recently by crystallographic studies. ${ }^{3-5}$ Activated cisplatin can also interact with other molecules in the cellular environment, like peptides (glutathione), or peptides with sulphur-containing amino acids, cysteine, and methionine, ${ }^{6-10}$ or RNAs. ${ }^{11}$ However, before all such interactions could occur, cisplatin must undergo the activation process. This activation consists of the chloro-ligand(s) replacement usually by water molecule(s).

Various aspects of cisplatin hydration have been studied in many laboratories for a very long time, for example, refs. 12-18
As to experimental works, the thermodynamic data for replacement of chloride ligand by water molecules were measured by Hindmarch et al. ${ }^{19}$ for both hydration steps:

$$
\begin{aligned}
\text { cis }-\left[\mathrm{Pt}\left(\mathrm{NH}_{3}\right)_{2} \mathrm{Cl}_{2}\right]+\mathrm{H}_{2} \mathrm{O} \stackrel{K_{1}}{\rightleftarrows} \mathrm{Cl}^{-}+ & \text {cis } \\
& -\left[\mathrm{Pt}\left(\mathrm{NH}_{3}\right)_{2} \mathrm{Cl}\left(\mathrm{H}_{2} \mathrm{O}\right)\right]^{+}
\end{aligned}
$$

Correspondence to: J. Burda; e-mail: burda@karlov.mff.cuni.cz Contract/grant sponsor: NSF-MŠMT; contract/grant number: ME-517, 1P05ME784 (to J.V.B.)

Contract/grant sponsor: GAUK; contract/grant number: 2003/181/B_CH (to M.Z.)

Contract/grant sponsor: ONR; contract/grant number: N00014-98-1-0592 (to J.L.)

Contract/grant sponsor: NSF-CREST; contract/grant number: 9805465 (to J.L.) 


$$
\begin{aligned}
\text { cis }-\left[\mathrm{Pt}\left(\mathrm{NH}_{3}\right)_{2} \mathrm{Cl}\left(\mathrm{H}_{2} \mathrm{O}\right)\right]^{+}+\mathrm{H}_{2} \mathrm{O} \stackrel{\mathrm{K}_{2}}{\rightleftarrows} \mathrm{Cl}^{-}+\text {cis } \\
-\left[\mathrm{Pt}\left(\mathrm{NH}_{3}\right)_{2}\left(\mathrm{H}_{2} \mathrm{O}\right)_{2}\right]^{2+}
\end{aligned}
$$

In $1.0 \mathrm{M} \mathrm{NaClO}_{4}$ solution it was found that the values of equilibrium constants can be expressed as $\log K_{1}=-2.19$ and $\log K_{2}=-3.53$. For analogous processes in the case of transplatin, the measurements were done by Arpalahti et al. ${ }^{20,21}$ They found slightly smaller hydration constants: $\log K_{1}=-2.92$ a $\log K_{2}=$ -4.41 in $0.1 \mathrm{M} \mathrm{NaClO}_{4}$ solution. Depending on the $\mathrm{pH}$ value of the environment, the hydrated complexes can be subsequently stabilized by deprotonation of the aqua ligands. ${ }^{22}$ This means that in the basic solutions, platinum complexes are again passivated:

$$
\begin{aligned}
& c i s-\left[P t\left(\mathrm{NH}_{3}\right)_{2} \mathrm{Cl}\left(\mathrm{H}_{2} \mathrm{O}\right)\right]^{+} \stackrel{K_{a 3}}{\rightleftarrows} H^{+}+\operatorname{cis}-\left[\mathrm{Pt}\left(\mathrm{NH}_{3}\right)_{2} \mathrm{Cl}(\mathrm{OH})\right] \\
& \operatorname{cis}-\left[\mathrm{Pt}\left(\mathrm{NH}_{3}\right)_{2}\left(\mathrm{H}_{2} \mathrm{O}\right)_{2}\right]^{2+} \stackrel{K_{a 1}}{\rightleftarrows} H^{+}+\operatorname{cis}-\left[\mathrm{Pt}\left(\mathrm{NH}_{3}\right)_{2}\left(\mathrm{H}_{2} \mathrm{O}\right)\right.
\end{aligned}
$$

cis $-\left[\mathrm{Pt}\left(\mathrm{NH}_{3}\right)_{2}\left(\mathrm{H}_{2} \mathrm{O}\right)(\mathrm{OH})\right]^{+} \stackrel{K_{\mathrm{a} 2}}{\rightleftarrows} H^{+}+\mathrm{cis}$

$$
-\left[\mathrm{Pt}\left(\mathrm{NH}_{3}\right)_{2}(\mathrm{OH})_{2}\right]
$$

Various values of $\mathrm{pK}_{\mathrm{a}}$ were determined for both cisplatin and transplatin in several studies, for example, refs. 23-26. Based on these measurements, approximate values of individual $\mathrm{pK}_{\mathrm{a}}$ are as follows: $\mathrm{pK}_{\mathrm{a} 1}=5.5, \mathrm{pK}_{\mathrm{a} 2}=7.3, \mathrm{pK}_{\mathrm{a} 3}=6.6, \mathrm{pK}_{\mathrm{a} 1}=4.4, \mathrm{pK}_{\mathrm{a} 2}=$ 7.3 , and $\mathrm{pK}_{\mathrm{a} 3}=5.6$, respectively, for the cisplatin and transplatin complexes. It should be noticed the hydrated transplatin deprotonates in the first step more readily (or at lower $\mathrm{pH}$ ) than cisplatin. The same is also true for the corresponding singly hydrated platinum complexes $\left(\mathrm{pK}_{\mathrm{a} 3}\right)$.

In addition to the equilibrium constants, the kinetic parameters of the hydration processes were studied. ${ }^{19-21,27}$ It is generally accepted that the substitution reactions occur predominately by associative mechanism in the case of $\mathrm{Pt}(\mathrm{II})$, and that this is a common mechanism for the transition metals. ${ }^{28}$ Despite that, large bulky ligands can slow down the reaction course substantially switching to the alternative dissociative mechanism is not probable in these cases. ${ }^{29}$ Although the forward reaction can be regarded as a kinetic reaction of the pseudofirst-order, the reverse reaction follows the second-order kinetic formalism. Experimentally determined rate constants for dechlorination were published by Jestin, ${ }^{27}$ Hindmarsch, ${ }^{19}$ or Arpalahti et al. ${ }^{20,21}$ for the first and second steps and both cis- and trans-conformers at $T=318.2 \mathrm{~K}, \mathrm{pH} 2.8-3.4$ and $0.1 \mathrm{M} \mathrm{NaClO}_{4}$ solution, and they are used for the comparison with the present results in Table 4.

Despite a question if the equilibrium for the hydration process can be established, there is a factor, which facilitates this reaction. Namely, the lowering concentration of $\mathrm{Cl}^{-}$anions, when cisplatin passes from blood (where $\left[\mathrm{Cl}^{-}\right]$is about $100 \mathrm{mM}$ ) to cellular environment (with $\left[\mathrm{Cl}^{-}\right]$about $10-80 \mathrm{mM}$ ) is responsible for enhancing of this process. The chloride concentration further de- creases in cellular nucleus to ca. $4 \mathrm{mM}$. This forces the hydration process to proceed in higher extent, according to LeChatelierBraun-van Hoff's principle.

In this study, the investigations started in the previous calculations in the gas phase ${ }^{30}$ are further extended. From the analyses of the previously obtained results, it could be noticed that some additional external factor should be introduced, which would be able to distinguish the cleavage of $\mathrm{Pt}-\mathrm{Cl}$ and $\mathrm{Pt}-\mathrm{N}$ bonds. Such a factor can be recognized in the influence of the close surrounding. Therefore, the effect of implicit solvent was chosen to perform such investigations. Based on preliminary calculations, the COSMO (Conductor-like screening solvation model) with unitedatom cavity was used. Similar calculations with the $\mathrm{Pt}(\mathrm{II})$ complexes were carried out by Zhang et al., ${ }^{31}$ who studied the dechlorination reactions using several DFT functionals. They used similar basis sets and PCM (Polarizable Continuum Model). This group has later published two other studies involving the platinum complexes. ${ }^{32,33}$ Other calculations devoted to the hydration of $\mathrm{Pt}$ complexes appeared recently. ${ }^{34,35}$ Here, the authors gave a thorough insight on the effect of various contributions in multipole expansion of SCRF (Self-Consistent Reaction Field). Despite the fact that they have focused on dechlorination of the Pt(II)-ethylenediammine complex, the obtained hydration characteristics are very close to the cisplatin data. Such a conclusion provides confidence to the reliability of the computational approaches because there is close relationship between the ciplatin and $\mathrm{Pt}(\mathrm{en}) \mathrm{Cl}_{2}$ complexes. Robertazzi et al. ${ }^{36}$ explored discrete solvation surface of cisplatin. They obtained the TS barrier of the cisplatin dechlorination about $1 \mathrm{kcal} / \mathrm{mol}$ lower in comparison with Zhang et al. ${ }^{31}$ Recent theoretical paper on cisplatin was published by Deubel. ${ }^{37}$ He examined different factors that can govern competition between nitrogen and sulphur ligands. Some other computational works dealing with cisplatin topics were already discussed in our previous studies. ${ }^{38-46}$

\section{Computational Model}

The present study is based on the supermolecular approach where both reactants and products are treated as a one molecular complex. These molecular complexes were considered to be neutral and in the singlet electronic ground state.

Because a dominant effect of solute-solvent interaction is of electrostatic origin, one of the possible approaches used to study such phenomena is to replace the explicit solvent molecules by dielectric continuum. This continuum is represented by polarization charges appearing on finite-size elements on the boundary surface between the solute and the continuum. ${ }^{47}$ This is the common description for the whole class of the so-called Apparent Surface Charges methods (ASC). The COSMO belongs to this ASC group also. The advantage of COSMO lies in better description of the systems in solvent with high permitivity ${ }^{48}$ so that it is suitable for simulation of a water environment. The United Atomic Topological Model (UATM) was used for building the cavity. In UATM, hydrogen atoms are not surrounded by their own cavity sphere but they are considered as a subpart of cavity sphere of the hydrogen-bonded atom. This strategy reduces the number of spheres and still provides high enough accuracy, as pointed by 


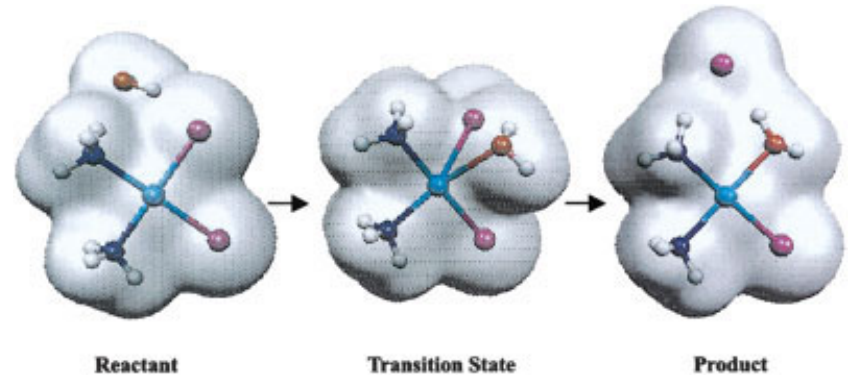

Figure 1. Supermolecular description of the reaction coordinate. United-atom cavity was chosen for implicit water description by COSMO method.

Tomasi ${ }^{47,49}$ and Amovilli. ${ }^{50}$ The second advantage of this choice is faster and a better convergence of the method. The utilization of the supermolecular model for hydration reaction of cisplatin is schematically depicted in Figure 1.

The solvation model for cis-/transplatin assumes two steps of the reaction. In the first step, one of the platinum ligands $\left(\mathrm{Cl}^{-}\right.$or $\mathrm{NH}_{3}$ ) is replaced by an explicitly considered water moleculereactions labeled as r01-r04. (For the numbering of the reactions, reactants, TS, and products, see Fig. 3.) Cisplatin is involved in the dechlorination (r01) and deammination (r02) processes, while transplatin participates in analogous reactions (r03) and (r04). The second step models further propagation of hydration reaction by replacing the next ligand (either $\mathrm{Cl}^{-}$or $\mathrm{NH}_{3}$ ) by water. To keep the supermolecular system neutral, those $\mathrm{Pt}(\mathrm{II})$ complexes, in which the first exchanged ligand was $\mathrm{Cl}^{-}$, had to be "modified" by replacing the aqua ligand with a hydroxyl group. The thermodynamic and kinetic parameters of the process of aqua ligand deprotonation are not examined in this study.

The designed molecular complexes of reactants, products, and transition states were optimized using the Becke3LYP functional of the DFT technique and the COSMO method. Pople's 6-31+G(d) AO basis set was used for the first row elements. The chlorine and platinum atoms were described with energy averaged relativistic pseudopotentials from Stuttgart-Dresden laboratory la-
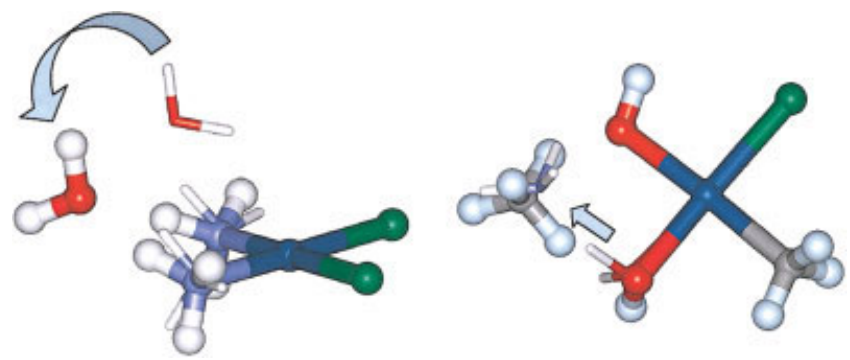

Figure 2. Superimposed optimized geometries from the gas-phase and COSMO calculations for: (a) reactant supermolecule of hydration process $\mathrm{r} 01$ : cis- $\mathrm{Pt}\left(\mathrm{NH}_{3}\right)_{2} \mathrm{Cl}_{2}+\mathrm{H}_{2} \mathrm{O}$ - arrow points to the change of water position passing from gas phase (thin sticks) to PCM structure (ball and stick). (b) Product supermolecule p10: neutral (gas phasethin sticks) and ion pair structures (PCM-ball and stick). Arrow shows the proton transfer from aqua-ligand to released $\mathrm{NH}_{4}$ particle.

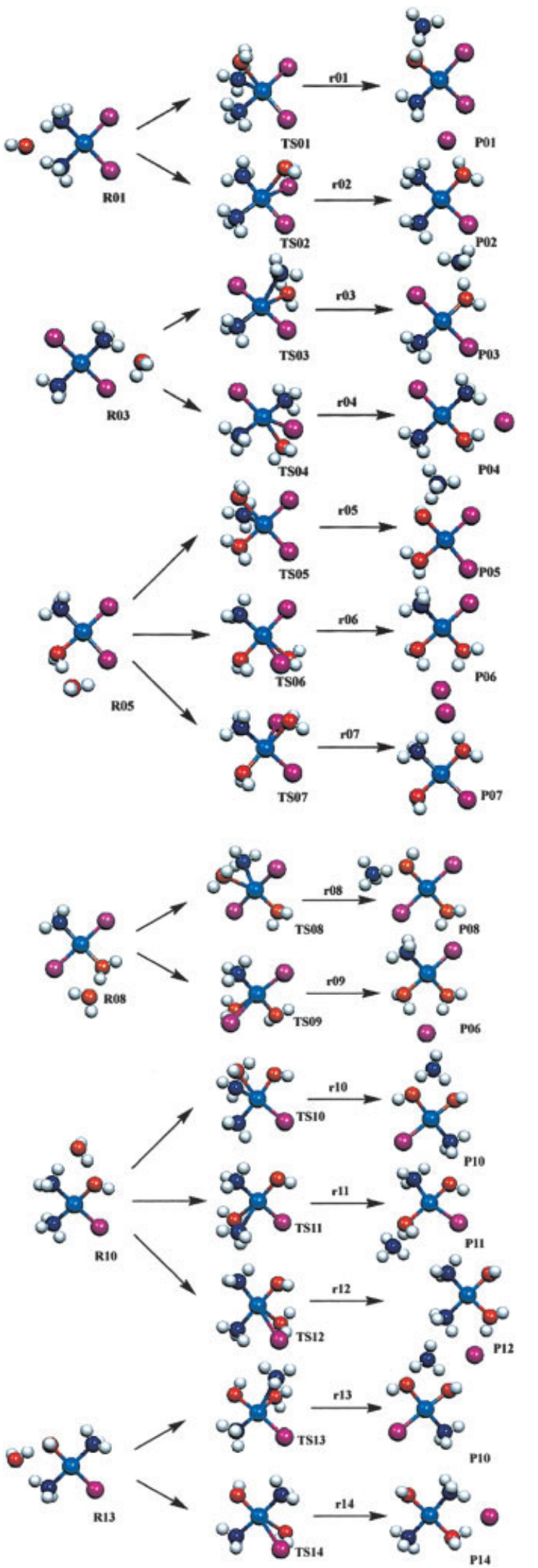

Figure 3. Optimized structures of reactants, transition states, and products, as well as the labeling used in the study. 
beled MWB- $10^{51}$ and MWB- $60,{ }^{52}$ respectively. The recommended atomic pseudoorbitals were augmented with the adequate diffuse and polarization functions to create well-balanced basis set. Exponent of the Pt polarization $\mathrm{f}$ function (0.998) was assumed as suggested in ref. 53.

The $\operatorname{CCSD}(\mathrm{T})$ method with a $6-31++\mathrm{G}(\mathrm{d}, \mathrm{p})$ basis set and the COSMO formalism was used for the evaluation of a single-point energy analysis. Active space contained all the orbitals except those belonging to frozen core electrons ( $1 \mathrm{~s}$ of the $\mathrm{O}$ and $\mathrm{N}$ atoms; inner electrons of $\mathrm{Pt}$ and $\mathrm{Cl}$ were cover within the ECP approach). The temperature of $T=310 \mathrm{~K}$ was used for the determination of thermochemical quantities.

The kinetic parameters of the studied reactions can be determined according to the Eyring's Transition State Theory (TST). Because vibrational modes, energies and geometry parameters can be obtained from the above-described calculations, the rate constants follow from the formula:

$$
k^{\mathrm{TST}}(T)=\frac{k T}{\hbar} \cdot \frac{F^{\mathrm{TS}}}{F^{\mathrm{Pt}} F^{w}} \cdot \exp \left(E_{0} / k T\right)
$$

where $F^{\mathrm{X}}$ means molecular partition functions per unit volume for TS, Pt complex, and water. $E_{0}$ is the activation barrier energy for the examined reaction coordinate. Here, it should be stressed that not all the global minima could be considered as a starting point for the given coordinate. Sometimes, additional conformational changes must occur where water molecule is localized in different geometrical part of the considered Pt complex. Because $k^{\mathrm{TST}}$ is exponentially dependent on the energy difference between reactant and TS structure, such a correction represents nonnegligible change in the final rate constant. Determination of $k^{\text {TST }}$ was performed by the DOIT program (Dynamics of Instanton Tunneling) generously provided by Z. Smedarchina. ${ }^{54}$ Partial charge analyses were determined by Natural Population Analysis (NPA) procedure suggested by Weinhold ${ }^{55,56}$ at the Becke3LYP/6$31+\mathrm{G}(\mathrm{d})$ level. The quantum chemical calculations were carried out using the Gaussian 98 program.

\section{Structure of the Pt(II) Complexes}

The $\mathrm{Pt}-\mathrm{L}$ distances in optimized structures are summarized in Table 1. From the table, two basic features can be noticed. First, all the distances are increased under the solvent effects, which truly reflects the fact that some portion of the electron density of $\mathrm{Pt}$ complexes is involved in the interactions with surrounding solvent molecules in more realistic models. Second, the largest differences in comparison with gas phase structures occur for the Pt-L distances between metal and the weakly bonded remote particles. This can be explained by the fact that these remote particles are also attracted by the electrostatic charge induced on the cavity surface (simulating the interactions with solution). The largest difference in the molecular parameters occurs in cisplatin + water complex. The main change can be seen in the shift of the H-bonded water from its position above the Pt complex plane in the gas phase case towards the plane in the COSMO case, cf. Figure 2a. Usually weakly bonded particles (water, ammonium, or chloride) were stabilized in the complex plane in both isolated and COSMO structures. Arrangement with a remote particle above the complex plane is very rare because sufficient additional stabilization is required in this case. Such a stabilization can be found in the electrostatic interaction between one of the water protons and the negatively charged chloride ligands in the cisplatin + water complex. Passing from the gas phase to liquid phase model, the most important change involves the screening of electrostatic forces. ${ }^{57}$ This is also reflected in these model calculations. The additional electrostatic $\mathrm{H}$. . .Cl forces were decreased so that the water molecule could not be kept above the Pt plane any longer, and it is transferred towards the complex plane. Comparing the gas phase and COSMO, the average difference in the $\mathrm{Pt}-\mathrm{L}$ dative bonds is about $0.04 \AA$.

It can be observed that the TS structures resemble closer products than the reactants. For example, the bonding distance for arriving ligand $(\mathrm{Pt}-\mathrm{O})$ is always shorter than $\mathrm{Pt}-\mathrm{N}$ for the departing ammonium ligand despite the shorter $\mathrm{Pt}-\mathrm{N}$ bonds in the reactant or product complexes. This is in good accord with the Hammond postulate because the hydration reactions are endothermic (as will be discussed below).

Another related difference between the results of the gas phase and COSMO approach reflects the change of reaction coordinate in most of the cases of the deammination reactions (cf. Fig. 2b and 3). The ion-pair structures in the frame of supermolecule are formed as the products in both hydration steps. The $\mathrm{NH}_{4}^{+}$particle is released from platinum complex instead of the ammonia molecule. The extra proton is taken from the ligated water. The preference for $\mathrm{NH}_{4}^{+}$cation is about $2.6 \mathrm{kcal} / \mathrm{mol}$. Consequently, the difference between the gas phase product conformers $\mathrm{p} 10$ and $\mathrm{p} 13$ disappears. The formation of the ion-pair structure is in good accordance with the quantum chemical calculations of amino acids. There, a formation of the $\mathrm{NH}_{2}-\mathrm{COOH}$ structure represents the most stable arrangement in the gas phase calculations, while $\mathrm{NH}_{3}^{+}-\mathrm{COO}^{--}$ zwitterions become the global minima in the studies employing PCM techniques. This was for the first time mentioned by Tomasi ${ }^{58}$ for glycine and later by others. ${ }^{59,60}$ Except for the different character of the product, the transfer from $\mathrm{NH}_{3}$ to $\mathrm{NH}_{4}^{+}$does not change the position of the remote particle substantially. As it is demonstrated in Table 1 and in Figure $2 b$, the remote particle remains in very similar position in both the gas phase and COSMO models.

\section{Thermodynamics and Activation Energies}

Single-point CCSD(T) energies were evaluated for the optimized structures of the reactant and product supermolecules as well as for the TS. The final reaction Gibbs free energies of the hydration processes and their activation barriers are summarized in Table 2, where also the results for gas phase calculations are included. At a first glance, one can notice that practically all the hydration energies are decreased by several $\mathrm{kcal} / \mathrm{mol}$ in comparison with the gas phase results. The reaction energies are usually slightly lower for the chloride replacement. The lowest $\Delta G$ hydration energies are predicted in both steps of cisplatin dechloration-6.7 and 8.4 $\mathrm{kcal} / \mathrm{mol}$. On the contrary, the deammination of cisplatin is accompanied with the largest increase of energy: about $12.8 \mathrm{kcal} / \mathrm{mol}$ 
Table 1. The Optimized Pt-L Distances between Pt and the N, O, or Cl Atom (in Å) Using COSMO and the Comparison with Gas Phase Calculations.

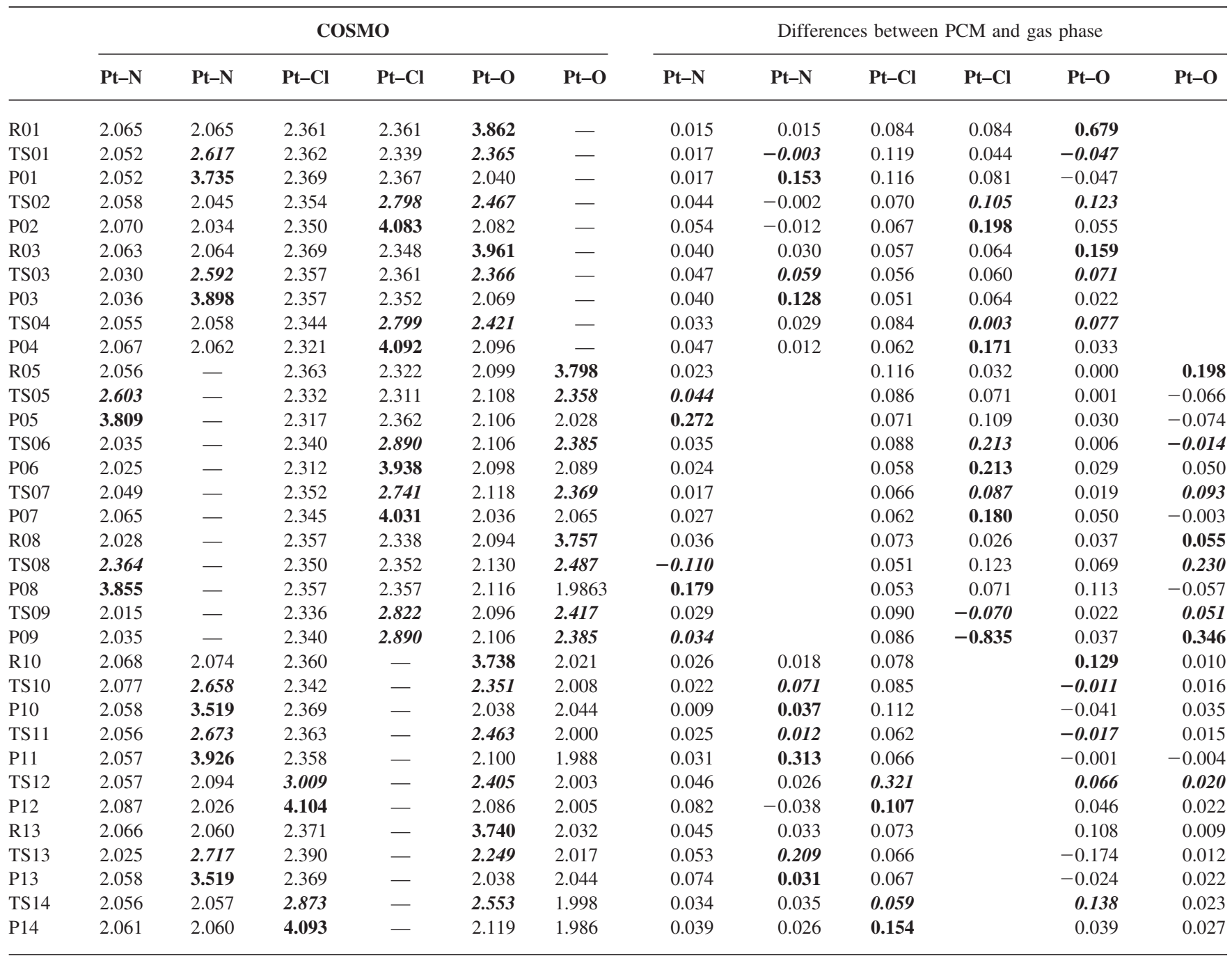

Bold font assigns the heavy atom of the remote particle, italic + bold font labels the exchanging particles in TS structures.

in the first and $12.9 \mathrm{kcal} / \mathrm{mol}$ in the second step. Such trends were not observed in the gas phase calculations. Moreover, the lowest Gibbs energy in the gas phase is connected with the deammination processes $\mathrm{r} 01(8.7 \mathrm{kcal} / \mathrm{mol})$ and $\mathrm{r} 10(8.1 \mathrm{kcal} / \mathrm{mol})$.

As stated in the Introduction, the first hydration-dechlorination step (r02 and r04) can be compared with the value of $\Delta G=3.1$ $\mathrm{kcal} / \mathrm{mol}$ for cisplatin and $\Delta G=4.1$ for transplatin obtained from experimental studies ${ }^{20,21}$ where equilibrium constants were determined as $\mathrm{pK}_{1}=2.19$ and 2.92 for both cis- and transplatin, respectively. It can be seen that the inclusion of environmental effects substantially improves the predicted energies. The deviation of about $3-5 \mathrm{kcal} / \mathrm{mol}$ can be considered as an error bar of the model used for calculations and also some uncertainty should be connected with the determination of experimental values of $\mathrm{pK}$. The similar comparison can be done for the second step, hydration processes $\mathrm{r} 12$ and $\mathrm{r} 14$, combining reactions $K_{\mathrm{a} 3}-K_{2}-K_{\mathrm{a} 1}$ from eqs. (1) and (2). The evaluation of the corresponding Gibbs energies gives $\Delta G_{2}^{*}=\Delta G_{2}+\Delta G_{\mathrm{a} 1}-\Delta G_{\mathrm{a} 3}$ (assuming the same temperature in all three measurements $T=310 \mathrm{~K}$ ). In this way, Gibbs energies $\Delta G_{2}^{*}=3.4$ and $4.6 \mathrm{kcal} / \mathrm{mol}$ can be predicted for cis- and transplatin, respectively. Here, however, the uncertainty in the "experimental" $\Delta G_{2}^{*}$ values is higher. One can conclude that despite the fact that the calculated energies do not exactly match the experimental data, the correct trend for going from the gas phase to COSMO values is reproduced.

Comparing our results with the analogous data of Zhang, ${ }^{31}$ very good agreement can be observed. However, it can be noticed that for the second hydration step they started with slightly different charged reactant cis- $\left[\mathrm{Pt}\left(\mathrm{NH}_{3}\right)_{2} \mathrm{Cl}\left(\mathrm{H}_{2} \mathrm{O}\right)\right]^{+}+\mathrm{H}_{2} \mathrm{O}$ and they obtained slightly higher reaction energy of $14.1 \mathrm{kcal} / \mathrm{mol} \mathrm{vs}$. our 
Table 2. Gibbs Energies and Activation Barriers (in $\mathrm{kcal} / \mathrm{mol}$ ) at the $\operatorname{CCSD}(\mathrm{T}) / 6-31++\mathrm{G}(\mathrm{d}, \mathrm{p})$ Level of Calculations for $T=310 \mathrm{~K}$.

\begin{tabular}{lrrrrr}
\hline & \multicolumn{2}{c}{$\Delta G_{r}$} & & \multicolumn{2}{c}{$\Delta E_{a}$} \\
\cline { 2 - 3 } \cline { 5 - 6 } Reaction & Cosmo & Gas ph. & & Cosmo & Gas ph. \\
\hline & 12.8 & 8.7 & & 32.3 & $28.9^{\mathrm{a}}$ \\
r01 & 6.7 & 10.2 & & 22.7 & 26.8 \\
r02 & 11.5 & 13.8 & & 31.1 & 33.6 \\
r03 & 9.4 & 17.8 & & 21.5 & 29.4 \\
r04 & 10.1 & 15.2 & 30.9 & $35.1^{\mathrm{a}}$ \\
r05 & 7.0 & 9.7 & 24.7 & 28.4 \\
r06 & 12.6 & 18.6 & 25.4 & 34.4 \\
r07 & 12.9 & 19.9 & 32.6 & $40.9^{\mathrm{a}}$ \\
r08 & 11.4 & 16.9 & 26.5 & 34.0 \\
r09 & 10.9 & 8.1 & 35.8 & $30.6^{\mathrm{a}}$ \\
r10 & 9.4 & 12.4 & 33.6 & 34.3 \\
r11 & 8.4 & 16.5 & 24.5 & 29.9 \\
r12 & 12.2 & 15.2 & 35.1 & $38.2^{\mathrm{a}}$ \\
r13 & 10.7 & 20.6 & 24.6 & 34.0 \\
r14 & & & & \\
\hline
\end{tabular}

${ }^{\mathrm{a}} \mathrm{NH}_{3}$ molecule released in gas phase.

value of $7.8 \mathrm{kcal} / \mathrm{mol}$ (or $\Delta G=8.4 \mathrm{kcal} / \mathrm{mol}$ ) for the neutral complex of cis- $\mathrm{Pt}\left(\mathrm{NH}_{3}\right)_{2} \mathrm{Cl}(\mathrm{OH})+\mathrm{H}_{2} \mathrm{O}$. This is in good accord with the lower stabilization of cisplatin in diaqua than the aquahydroxo-form.

The TS structures are based on the associative mechanism with the 5-coordinated trigonal-bipyramidal arrangement. The last two columns of Table 2 contain the information about the reaction barriers heights. The differences between the energies of the optimized TS structures and their reactant conformers, which were obtained going downhill from these TS [using Intrinsic Reaction Coordinate (IRC) algorithm], were used for the determination of the $\Delta E_{a}$ activation energies at the $\operatorname{CCSD}(\mathrm{T})$ level of calculation. For instance, the proper reaction coordinate for the process of cisDDP dechloration ( $\mathrm{r} 02$ ) does not start in the global minimum structure, as can be seen in Figure 3. Instead, another conformer must be considered where the water molecule is transferred to the next quadrant of the Pt complex to be able to interact with the $\mathrm{Cl}$ ligand. From the last part of Table 2, it is clearly visible that all the dechlorination reactions have substantially lower reaction barriers than the corresponding deammination processes. This trend was also partially visible from the gas phase results, however not so clearly and unambiguously. Relatively large differences between dechlorination and deammination occur in the first hydration step, about $10 \mathrm{kcal} / \mathrm{mol}$ for both cis-/transplatin complexes. In the second step, the difference is slightly smaller, but it still remains over $6 \mathrm{kcal} / \mathrm{mol}$. These differences distinctly speak out for the kinetic preference of the dechlorination process (cf. Discussion below).

For the deammination processes (with exclusion of r04) the ligand exchange and the proton transfer from water to ammonia occur simultaneously within the reaction course. However, the heights of the activation barriers are not affected by this fact, because the proton transfer starts on the reaction coordinate a little later after passing the TS structure, going already downhill towards products on the Gibbs free energy surface.
The association energies of platinum complexes with the water, ammonia, or chloride particle were determined at the $\operatorname{CCSD}(\mathrm{T}) /$ $6-31++$ G(d.p) level. The obtained results are collected in Table 3 and compared with calculations of isolated supermolecule. From Table 3, it is apparent that the H-bond interactions of the water molecule with the $\mathrm{Pt}$ complex are decreased in the COSMO, in average by about $5 \mathrm{kcal} / \mathrm{mol}$. In the case of the $\mathrm{NH}_{3}$ or $\mathrm{NH}_{4}^{+}$ particles, the changes are practically negligible. The most illustrating cases represent the products of the dechlorination processes because the remarkable reduction of the association energies was achieved. The explanation insists in the efficient screening of the electrostatic interaction between the positively charged platinum complex and the chloride particle. However, this fact does not mean that electrostatic forces were diminished because the other Coulombic interactions based on the induced charges were introduced. As a consequence, the bulk water environment efficiently compensates the electrostatic work, which is necessary for the separation of the two charge carriers (the $\mathrm{Cl}^{-}$anion and $[\mathrm{Pt}$ complex $]^{+}$as well as the $\mathrm{NH}_{4}^{+}$cation and $[\mathrm{Pt} \text { complex }]^{-}$).

\section{Evaluation of the Rate Constants}

The TST rate constants determined according to the eq. (3) are collected in Table 4, together with the corresponding $\Delta G\left[=R T \ln \left(k_{1} / k_{-1}\right)\right]$ values. The rate constants for hydration-dechlorination processes in the first step are generally about four orders of magnitude higher than the corresponding values for the deammination reactions. For the replacement of the second water

Table 3. The Association Interactions between Both Parts of the Supermolecule (in $\mathrm{kcal} / \mathrm{mol})$.*

\begin{tabular}{crc}
\hline $\mathrm{H}_{2} \mathrm{O}+$ reactant: & Gas phase & COSMO \\
\hline $\mathrm{R} 01$ & -10.4 & -5.8 \\
$\mathrm{R} 03$ & -9.2 & -2.9 \\
$\mathrm{R} 05$ & -13.8 & -7.4 \\
$\mathrm{R} 08$ & -12.7 & -7.4 \\
$\mathrm{R} 10$ & -12.7 & -8.3 \\
$\mathrm{R} 13$ & -13.5 & -8.8 \\
$\mathrm{NH}_{4}+$ product & & \\
$\mathrm{P} 01$ & -15.6 & -12.7 \\
$\mathrm{P} 03$ & -14.7 & -16.3 \\
$\mathrm{P} 05$ & -15.0 & -11.0 \\
$\mathrm{P} 08$ & -16.5 & -16.7 \\
$\mathrm{P} 10$ & -15.8 & -15.7 \\
$\mathrm{P} 11$ & -11.6 & -13.6 \\
$\mathrm{Cl}^{-}+$product & & \\
$\mathrm{P} 02$ & -112.5 & -8.3 \\
$\mathrm{P} 04$ & -116.9 & -5.4 \\
$\mathrm{P} 06$ & -121.0 & -9.0 \\
$\mathrm{P} 07$ & -117.0 & -4.8 \\
$\mathrm{P} 12$ & -109.5 & -2.4 \\
$\mathrm{P} 14$ & -111.5 & -1.9 \\
\hline
\end{tabular}

*Labels the two reactions where the deammination product supermolecule contained neutral $\mathrm{NH}_{3}$ molecule instead of $\mathrm{NH}_{4}^{+}$cation in the COSMO calculations. 
Table 4. Rate Constants for Forward and Reversed Hydration Reactions and $\Delta G$ Calculated from the Rate Constants Ratio.

\begin{tabular}{|c|c|c|c|}
\hline & $k_{1}$ & $k_{-1}$ & $\Delta G$ \\
\hline r01 & $1.7 \mathrm{E}-09$ & 1.9 & 12.8 \\
\hline r02 & $1.3 \mathrm{E}-04$ & $8.4 \mathrm{E}+01$ & 8.2 \\
\hline $\exp ^{a}$ & $(1.9 \pm 0.2) \mathrm{E}-4$ & $(6.0 \pm 1.5) \mathrm{E}-2$ & 3.5 \\
\hline $\exp ^{c}$ & $5.2 \mathrm{E}-5$ & $7.6 \mathrm{E}-3$ & 3.1 \\
\hline $\exp ^{d}$ & $(1.12+0.02) \mathrm{E}-4$ & & \\
\hline $\exp ^{\mathrm{e}}$ & $1.6 \mathrm{E}-4$ & & \\
\hline $\exp ^{f}$ & $1.0 \mathrm{E}-4$ & & \\
\hline $\exp ^{g}$ & $1.1 \mathrm{E}-4$ & & \\
\hline r03 & $1.1 \mathrm{E}-08$ & $1.7 \mathrm{E}-01$ & 10.2 \\
\hline r04 & $5.4 \mathrm{E}-04$ & $3.1 \mathrm{E}+02$ & 8.2 \\
\hline $\exp ^{b}$ & $(1.1 \pm 0.1) \mathrm{E}-3$ & $2.2 \pm 0.4$ & 4.7 \\
\hline r05 & $2.7 \mathrm{E}-10$ & $5.5 \mathrm{E}-01$ & 13.2 \\
\hline r06 & $2.1 \mathrm{E}-04$ & $8.8 \mathrm{E}-01$ & 5.1 \\
\hline r07 & $5.6 \mathrm{E}-07$ & $5.4 \mathrm{E}+01$ & 11.3 \\
\hline r08 & $9.5 \mathrm{E}-09$ & $2.2 \mathrm{E}+00$ & 11.9 \\
\hline r09 & $3.5 \mathrm{E}-04$ & $7.7 \mathrm{E}+02$ & 9.0 \\
\hline r10 & $4.5 \mathrm{E}-10$ & $6.3 \mathrm{E}-03$ & 10.1 \\
\hline r11 & 2.6E-09 & $1.7 \mathrm{E}-01$ & 11.1 \\
\hline r12 & 4.4E-06 & $1.4 \mathrm{E}+01$ & 9.2 \\
\hline $\exp ^{a}$ & $(2.3 \pm 0.3) \mathrm{E}-04$ & $(9.9 \pm 1.4) \mathrm{E}-01$ & 5.2 \\
\hline $\exp ^{\mathrm{e}}$ & $8.0 \mathrm{E}-5$ & & \\
\hline $\exp ^{h}$ & $2.0 \mathrm{E}-5$ & & \\
\hline r13 & $3.8 \mathrm{E}-11$ & 3.1E-01 & 14.1 \\
\hline r14 & 2.4E-04 & $1.01 \mathrm{E}+02$ & 8.0 \\
\hline $\exp ^{b}$ & $(4 \pm 2) \mathrm{E}-06$ & $(2.0 \pm 0.2) \mathrm{E}-04$ & 2.4 \\
\hline
\end{tabular}

${ }^{\mathrm{a}}$ ref. 20; ${ }^{\mathrm{b}}$ ref. 21 ; ${ }^{\mathrm{c}}$ ref. $19 ;{ }^{\mathrm{d}}$ ref. 27 ; ${ }^{\mathrm{e}}$ ref. $61 ;{ }^{\mathrm{f}}$ ref. $62 ;{ }^{\mathrm{g}}$ ref. $27 ;{ }^{\mathrm{h}}$ ref. 63.

molecule, the difference decreases but still remains about three orders of magnitude. This means that the dechlorinations are kinetically preferred over deammination reactions The detection of the process, where ammonium is released, would be very difficult in a real sample because very low concentration of cisplatin (usually about $5 \mu$ ) is used.

For a comparison with experimental measurements, there are several results available, for example, refs. 19-21 and 27. From Table 4 , it follows that a very good agreement with experimental data was achieved. The compared results lie within an order of magnitude for forward reaction and slightly worse for reverse processes. For the second dechlorination step, reactions $\mathrm{r} 12$ and $\mathrm{r} 14$, the agreement with the published measurements is also fairly good but here slightly different reactions are considered, and unfortunately, there are no data for applying the kinetic parameters like in the thermodynamic part. Nevertheless, even so, the rate constants for the second step are not too far from the experimental data, and substantial improvement of the results obtained with the COSMO was achieved in comparison with the in vacuo calculation.

The last column of Table 4 contains the estimation of $\Delta G$ values calculated from $K=k_{1} / k_{-1}$ at $T=310 \mathrm{~K}$, and it can be seen that some deviations (up to $2.5 \mathrm{kcal} / \mathrm{mol}$ ) from the thermodynamic part above occur. However, similar discrepancies are also noticeable when experimental rate constants are transferred to $\Delta G$ energies and compared with the corresponding $\Delta G$ obtained from the $\mathrm{pK}$ values.

A comparison with other theoretical studies dealing with similar systems ${ }^{31,34,35}$ can be performed. However, these studies considered only the dechlorination reactions. Besides cisplatin, ethylenediammine-dichloro-Pt(II) complexes were studied. Zhang et al. $^{31}$ estimated their energetic and kinetic parameters from similar model, employing several PCM models and the DFT calculation with a double-zeta quality basis set and with the pseudopotential approach. Their results are in a very good accord with the relevant part of present data. Similarly, de Costa et al. ${ }^{34,35}$ made estimations of rate constants for $\mathrm{Pt}(\mathrm{en}) \mathrm{Cl}_{2}$ dechlorination combining the general Born-Onsager SCRF or PCM with DFT or MP2. They reported activation barriers of 32 and $23 \mathrm{kcal} / \mathrm{mol}$ for the gas phase and PCM, respectively. Also, their rate constants are fairly close to our results $\left(k_{1}=1.9 \mathrm{E}-11\right.$ for the gas phase, and $k_{1}=$ 4.8E-5 for the PCM). This similarity originates in large extent from chemical propinquity (or relations) of those $\mathrm{Pt}(\mathrm{II})$ complexes.

\section{Conclusions}

In the present study, the thermodynamic and kinetic aspects of hydration reactions of cis-/transplatin were explored. The COSMO model with Becke3LYP functional and 6-31+G(d) basis set of AO was used for optimization of the structures involved in hydration reactions and the estimation of their vibrational frequences. Determination of the interaction energies and activation barriers was performed at the $\operatorname{CCSD}(\mathrm{T}) / 6-31++\mathrm{G}(\mathrm{d}, \mathrm{p})$ level within the same COSMO approach for inclusion of the effects of polarizable continuum. The hydration of $\mathrm{Pt}$ complexes was considered in two steps. In each of them concurrent reactions were expected-dechlorination and deammination. An associative mechanism was assumed for the reaction course in which a trigonal-bipyramidal structure of TS was determined. From these results, Gibbs free energies and rate constants for the hydration were determined.

All the hydration reactions are slightly endothermic. The Gibbs energies for hydration of cisplatin are $\Delta G=6.7$ and $12.8 \mathrm{kcal} / \mathrm{mol}$ for the chloride and ammonium replacement, respectively. Analogous values for transplatin are 9.4 and $11.5 \mathrm{kcal} / \mathrm{mol}$. These dechlorination results match experimental data fairly accurately.

The activation of cisplatin can be regarded as purely based on thermodynamic properties because the stabilization energies are lowered within each hydration step by about $10 \mathrm{kcal} / \mathrm{mol}$. The lower the stabilization, the higher the reactivity. On the contrary, dissociation of aqua-ligands under higher $\mathrm{pH}$ leads to formation of hydroxyl and dihydroxyl complexes, which passivate cisplatin by increasing the stabilization energy of such complexes. The situation is also reflected by the results of the NPA where substantially lower donation effects for products than reactants are predicted in correspondence with larger positive charges on the Pt atom in the products

The determined rate constants are by several (three to four) orders of magnitude larger for dechlorination process than for deammination. Very good agreement with available experimental data was achieved. The cisplatin dechlorination rate constant was established as $k_{1}=1.3 \cdot 10^{-4} \mathrm{~s}^{-1}$ to compare with the experimental values $(1.9 \pm 0.2) \cdot 10^{-4}$ in ref. 20 or $(1.12+0.02) \cdot 10^{-4}$ in ref. 27. Despite the fact that the other results do not match measured values as accurately, they are still in close proximity of the experimental data. The corresponding results of other theoretical studies are in fair agreement with our predictions as well, for 
example, $\Delta G=7.1 \mathrm{kcal} / \mathrm{mol}$ obtained by Zhang et al. ${ }^{31}$ for the dechlorination reaction of cisplatin, or $\Delta E=7.6 \mathrm{kcal} / \mathrm{mol}$ in the model of cisplatin with 10 water molecules. ${ }^{36}$

\section{Acknowledgments}

The authors thank Meta-Centers in Prague (Charles University and Czech Technical University), Brno (Masaryk University), Pilsen (University of West Bohemia), and Mississippi Center for Supercomputing Research for the generous support of the computational resources.

\section{References}

1. Rosenberg, B.; Van Camp, L.; Trosko, J. L.; Mansour, V. H. Nature 1969, 222, 385.

2. Cohen, S. M.; Mikata, Y.; He, Q.; Lippard, S. J. Biochemistry 2000, 39, 11771 .

3. Lilley, D. M. J. J Biol Inorg Chem 1996, 1, 189.

4. Coste, F.; Malinge, J. M.; Serre, L.; Shepard, W.; Roth, M.; Leng, M.; Zelwer, C. Nucleic Acids Res 1999, 27, 1837.

5. Ziegler, C. J.; Sandman, K. E.; Liang, C. H.; Lippard, S. J. J Biol Inorg Chem 1999, 4, 402.

6. Djuran, M. I.; Lempers, E. L. M.; Reedijk, J. Inorg Chem 1991, 30, 2648.

7. Lempers, E. L. M.; Reedijk, J. Inorg Chem 1990, 29, 217.

8. Barnham, K. J.; Djuran, M. J.; Murdoch, P. d. S.; Ranford, J. D.; Sadler, P. J. Inorg Chem 1996, 36, 1065.

9. Barnham, K. J.; Bauer, C. J.; Djuran, M. I.; Mazid, M. A.; Rau, T.; Sadler, P. J. Inorg Chem 1995, 34, 2826.

10. Barnham, K. J.; Djuran, M. J.; Murdoch, P. d. S.; Sadler, P. J. J Chem Soc Chem Commun 1994, 721.

11. Kleine, M.; Wolters, D.; Sheldrick, W. S. J Inorg Biochem 2003, 97, 354.

12. Miller, S. E.; House, D. A. Inorg Chim Acta 1991, 187, 125.

13. Miller, S. E.; Gerard, K. J.; House, D. A. Inorg Chim Acta 1991, 190, 135.

14. Reedijk, J.; Teuben, J. M. In Cisplatin; Lippert, B., Ed.; Wiley-VCH: Weinheim, 1999.

15. Marzilli, L. G.; Saad, J. S.; Kuklenyik, Z.; Keating, K. A.; Xu, Y. J Am Chem Soc 2001, 123, 2764.

16. Lippert, B. Coord Chem Rev 2000, 200, 487.

17. Anorbe, M. G.; Luth, M. S.; Roitzch, M.; Cerda, M. M.; Lax, P.; Kampf, G.; Sigel, H.; Lippert, B. Chem A Eur J 2004, 10, 1046.

18. Sullivan, S. T.; Saad, J. S.; Fanizzi, F. P.; Marzilli, L. G. J Am Chem Soc 2002, 124, 1558.

19. Hindmarsh, K.; House, D. A.; Turnbull, M. M. Inorg Chim Acta 1997, 257, 11.

20. Arpalahti, J.; Mikola, M.; Mauristo, S. Inorg Chem 1993, 32, 3327.

21. Mikola, M.; Arpalahti, J. Inorg Chem 1994, 33, 4439.

22. Martin, R. B. In Cisplatin; Lippert, B., Ed.; Wiley-VCH: Weinheim, 1999, p 183.

23. Berners-Price, S. J.; Frenkiel, T. A.; Frey, U.; Randolf, J. D.; Sadler, P. J. J Chem Soc Chem Commun 1992, 789.

24. Orton, D. M.; Gretton, V. A.; Green, M. Inorg Chim Acta 1993, 204, 265.

25. Appleton, T. G.; Pescb, F. J.; Wienken, M.; Menzer, S.; Lippert, B. Inorg Chem 1992, 31, 4410.

26. Mikola, M.; Arpalahti, J. Inorg Chem 1996, 35, 7556.

27. Jestin, J.-L.; Lambert, B.; Chottard, J.-C. J Biol Inorg Chem 1998, 3, 515 .

28. Wilkins, R. G. Kinetics and Mechanism of Reactions of Transition Metal Complexes; VCH: Weinheim, 1991
29. Schmuelling, M.; Lippert, B.; van Eldik, R. Inorg Chem 1994, 33, 3276.

30. Burda, J. V.; Zeizinger, M.; Leszczynski, J. J Chem Phys 2004, 120, 1253.

31. Zhang, Y.; Guo, Z.; You, X.-Z. J Am Chem Soc 2001, 123, 9378.

32. Zhang, Y.; Zhang, L.; Tao, H. B.; Sun, X. J.; Zhu, L. G. Spectrochim Acta, Part A Mol Biomol Spectrosc 2003, 59, 493.

33. Zhang, L.; Zhang, Y.; Tao, H. B.; Sun, X. J.; Guo, Z. J.; Zhu, L. G. J Mol Struct Theochem 2002, 617, 87.

34. Costa, L. A. S.; Rocha, W. R.; De Almeida, W. B.; Dos Santos, H. F. Chem Phys Lett 2004, 387, 182.

35. Costa, L. A. S.; Rocha, W. R.; De Almeida, W. B.; Dos Santos, H. F. J Chem Phys 2003, 118, 10584.

36. Robertazzi, A.; Platts, J. A. J Comput Chem 2004, 25, 1060.

37. Deubel, D. V. J Am Chem Soc 2004, 126, 5999.

38. Deubel, D. V. J Am Chem Soc 2002, 124, 5834.

39. Wysokinski, R.; Michalska, D. J Comp Chem 2001, 22, 901.

40. Pavankumar, P. N.; Seetharamulu, P.; Yao, S.; Saxe, J. D.; Reddy, D. G.; Hausheer, F. H. J Comput Chem 1999, 20, 365.

41. Carloni, P.; Sprik, M.; Andreoni, W. J Phys Chem B 2000, 104, 823.

42. Burda, J. V.; Šponer, J.; Leszczynski, J. J Biol Inorg Chem 2000, 5, 178.

43. Burda, J. V.; Šponer, J.; Leszczynski, J. Phys Chem Chem Phys 2001, 3, 4404.

44. Šponer, J.; Šponer, J. E.; Gorb, L.; Leszczynski, J.; Lippert, B. J Phys Chem A 1999, 103, 11406.

45. Baik, M.-H.; Friesner, R. A.; Lippard, S. J. J Am Chem Soc 2002, 124, 4495.

46. Hill, G.; Gora, R. W.; Roszak, S.; Leszczynki, J. Int J Quantum Chem 2001, 83, 213.

47. Tomasi, J.; Cammi, R.; Mennucci, B.; Cappelli, C.; Corni, S. PCCP 2002, 4, 5697.

48. Klamt, A.; Eckert, F.; Hornig, M.; Beck, M. E.; Burger, T. J Comp Chem 2002, 23, 275.

49. Tomasi, J.; Cammi, R.; Mennucci, B. Int J Quantum Chem 1999, 775, 7783.

50. Amovilli, C.; Barone, V.; Cammi, R.; Cancès, E.; Cossi, M.; Mennucci, B.; Pomelli, C. S.; Tomasi, J. Adv Quantum Chem 1998, 32, 227.

51. Bergner, A.; Dolg, M.; Kuechle, W.; Stoll, H.; Preuss, H. Mol Phys 1993, 80, 1431.

52. Andrae, D.; Haussermann, U.; Dolg, M.; Stoll, H.; Preuss, H. Theor Chim Acta 1990, 77, 123.

53. Burda, J. V.; Zeizinger, M.; Sponer, J.; Leszczynski, J. J Chem Phys 2000, 113, 2224

54. Smedarchina, Z.; Fernández-Ramos, A.; Siebrand, W. J Comput Chem 2001, 22, 787.

55. Carpenter, J. E.; Weinhold, F. J of Mol Structure (Theochem) 1988, $169,41$.

56. Reed, A. E.; Weinhold, F. J Chem Phys 1983, 78, 4066.

57. Burda, J. V.; Šponer, J.; Hrabáková, J.; Zeizinger, M.; Leszczynski, J. J Phys Chem B 2003, 107, 5349.

58. Bonaccorsi, R.; Palla, P.; Tomasi, J. J Am Chem Soc 1984, 106, 1945.

59. Barone, V.; Adamo, C.; Grand, A.; Subra, R. Chem Phys Letters 1995, 242,351 .

60. Nielsen, P. A.; Norrby, P. O.; Liljefors, T.; Rega, N.; Barone, V. J Am Chem Soc 2000, 122, 3151 .

61. Segal-Bendirdjian, E.; Brehin, P.; Lambert, B.; Laousi, A.; Kozelka, J.; Barreau, M.; Lavalle, F.; LePecq, J. B.; Chottard, J.-C. Platinum and Other Metal Coordination Compounds in Cancer Chemotherapy; Plenum Press: New York, 1991

62. Bancroft, D. P.; Lepre, C. A.; Lippard, S. J. J Am Chem Soc 1990, 112,6860 .

63. Johnson, N. P.; Hoeschele, J. D.; Rahn, R. O. Chem-Biol Interact 1980, 30, 151. 